\title{
Awareness during Anesthesia_-Role of Benzodiazepines as a Premedicant
}

\author{
Ananda Bhat $^{1}$, Balajibabu Perumala Ramanna ${ }^{2}$, Ashwini Thimmarayappa ${ }^{3}$
}

\begin{abstract}
Background: Awareness during anesthesia is a frightening experience. Benzodiazepines like lorazepam have been used to decrease awareness and also to cause amnesia. However, there is insufficient evidence established regarding their efficacy and effectiveness. This study was carried out to evaluate the efficacy of benzodiazepines in minimizing the awareness during general anesthesia.

Methods: This randomized controlled trial was undertaken on 100 patients who underwent various elective surgical procedures. Each group consisted of 50 participants who were randomly allocated based on the computer-generated random numbers. The experimental group received midazolam as a premedicant in addition to atropine, while the control group received only atropine.

Results: In this study, the overall incidence of awareness was $16 \%$. The incidence was higher in the control group (24\%) compared to that in the experimental group (8\%). In the control group, awareness was characterized by hearing conversation/music in $58.3 \%$ of the participants, followed by remembrance of intraoperative events in $41.6 \%$ of the participants. In the experimental group, awareness was pertained to dreaming in all the four participants (100\%).
\end{abstract}

Conclusion: There was a significant higher incidence of awareness under anesthesia in the patients who had received only atropine as premedication. Hence, it is recommended to include benzodiazepine like midazolam, a water-soluble agent, routinely as a premedicant to decrease the incidence of awareness.

Keywords: Anesthesia, Awareness, Benzodiazepines, Premedication.

The Journal of Medical Sciences (2019): 10.5005/jp-journals-10045-00102

\section{INTRODUCTION}

Anesthesia has helped mankind by abolishing one of its worst enemies - pain. Anesthesia, although of great help to mankind, can cause untold misery and suffering if not administered properly. Awareness under general anesthesia is one of them. The history of memory for events under anesthesia is as old as the history of anesthesia itself. A significant problem of "awareness under anesthesia" only appeared after the introduction of muscle relaxants in anesthesia practice by Griffin and Johnson in 1942. Dr Mallison was a firm advocate of the biological product intocostrin. Like his contemporaries, he believed in Griffin and Johnson's technique of light anesthesia and spontaneous respiration with partial curarization. In contrast to this technique, full paralysis of diaphragm and controlled ventilation were advocated by the Liverpool School, which was also called the "The Liverpool Technique."

In the present day, the use of nitrous oxide as the sole anesthetic agent along with oxygen in a patient kept paralyzed with a neuromuscular blocking drug is a well-established method of anesthesia. While the key advantages of this method included adequate muscle relaxation and ensurance of alertness with minimal cardiorespiratory disturbance at the end of the surgery, the chief disadvantages were the awareness under anesthesia and questionability of adequate anesthetic depth.

Awareness during anesthesia is a frightening experience. Patients who experience awareness and recall during anesthesia describe auditory perceptions, the sensation of paralysis, anxiety, panic, helplessness, and powerlessness. The psychological sequelae of awareness are sleep disturbances, nightmare, anxiety and panic attacks, flashbacks, avoidance of medical examinations, and traumatic stress disorders. Historically, lowdose inhalational agents were added to blunt the hemodynamic \begin{tabular}{l}
\hline \hline${ }^{1-3}$ Department of Anesthesiology, Sri Jayadeva Institute of Cardio- \\
vascular Sciences and Research, Bengaluru, Karnataka, India \\
Corresponding Author: Ashwini Thimmarayappa, Department of \\
Anesthesiology, Sri Jayadeva Institute of Cardiovascular Sciences \\
and Research, Bengaluru, Karnataka, India, Phone: +919845534540 , \\
e-mail: docashwini@gmail.com \\
How to cite this article: Bhat A, Ramanna BP, Thimmarayappa A. \\
Awareness during Anesthesia-Role of Benzodiazepines as a Premedicant. \\
J Med Sci 2019:5(1):7-10. \\
Source of support: Nil \\
Conflict of interest: None \\
Ethical approval: Obtained
\end{tabular}

response and to abolish awareness. They had their own drawbacks. To overcome awareness, opioid agents like morphine, pethidine, and fentanyl were used. They alone were not very successful in eliminating the incidence of awareness totally.

Benzodiazepines like lorazepam have been used to decrease awareness and also to cause amnesia. However, there is insufficient evidence established regarding the efficacy and effectiveness of these benzodiazepines in reducing the awareness. There is, therefore, a need to evaluate the effect of benzodiazepines on the incidence of awareness during the surgery.

\section{Objectives}

This study was carried out:

- To estimate the incidence of awareness under general anesthesia.

- To analyze the effect of premedication with $2 \mathrm{mg}$ of midazolam in decreasing the incidence of awareness under general anesthesia. 


\section{Methodology}

\section{Study Setting and Participants}

This randomized controlled trial was undertaken by the Department of Anesthesiology of a tertiary teaching institution in Mysuru, Karnataka, for a period of one and a quarteryears. All the patients who underwent various elective surgical procedures during the study period were selected for the study. A total of 100 patients participated.

\section{Selection Criteria}

Adult patients between 18 and 45 years with American Society of Anesthesiologists (ASA) I and II physical status and those who underwent various elective surgical procedures were included for the study. Emergency surgeries, patients with hearing impairment, speech difficulty, psychiatric disorder, and history of alcohol or drug dependence were excluded.

\section{Ethical Approval and Informed Consent}

Approval was obtained from the Institutional Ethics Committee prior to the commencement of the study. Each participant was explained in detail about the study and informed consent was obtained prior to the procedure.

\section{Randomization and Allocation to Groups}

The study participants were grouped into two based on the premedication received. The experimental group received premedication with injection midazolam $2 \mathrm{mg}$ and injection atropine $0.6 \mathrm{mg}$ intravenous (IV) just before induction. The control group received standard premedication, which was injection atropine $0.6 \mathrm{mg}$ intravenously just before induction. Each group consisted of 50 participants who were randomly allocated based on computer-generated random numbers.

\section{Data Collection}

Vitals were monitored prior to the procedure and baseline values were recorded. All the patients were induced with injection thiopentone $5 \mathrm{mg} \mathrm{kg}^{-1}$ intravenously and intubation was facilitated by injection suxamethonium $1.5 \mathrm{mg} \mathrm{kg}^{-1}$. The patients were maintained on isoflurane $0.4 \%$ dial setting, $67 \%$ nitrous oxide in oxygen, and vecuronium $0.08 \mathrm{mg} \mathrm{kg}^{-1} \mathrm{IV}$ and were ventilated manually with Bain's circuit. All the patients received pethidine $50 \mathrm{mg}$ intravenously after intubation. Throughout the anesthetic procedure, flow rates of gases, i.e., nitrous oxide and oxygen, were not altered. Muscle relaxant was repeated at the first sign of attempts at respiration. Pulse rate, blood pressure, and $\mathrm{SpO}_{2}$ were monitored throughout the procedure.

All the patients were exposed to auditory stimuli like popular music, which was psychologically nontraumatic to the patient, throughout the procedure, using ear phones and a tape recorder.

At the end of the surgical procedure, neuromuscular blockade was antogonized by neostigmine and atropine in adequate doses.
After reversal of neuromuscular blockade, nitrous oxide was cut off and the lungs were ventilated with oxygen. The patients were asked to open the mouth. If there was no response, laryngoscopy and suction were carried out. This was repeated at 15 -second intervals. The time interval from the time of withdrawal of nitrous oxide till the patient made appropriate response to a verbal request was taken as "The time to correct response" (TCR).

All the patients were interviewed on the same evening of surgery and also on the postoperative day within 24 hours. Information on memory, dreams, and the entire experience of surgery was documented.

\section{Pretesting}

The questions regarding the awareness were structured and pretested on 10 participants for the purpose of validation. The results of the pilot study were not included in the analysis.

\section{Operational Definition}

Awareness under general anesthesia was taken as the ability of the patient to recall, with or without prompting, any event which occurred between induction of anesthesia and recovery of consciousness at the end of anesthesia. Recall of dreams that occurred during anesthesia was also considered as awareness. In this study, memory recall and the TCR test were taken into consideration, to study the awareness under anesthesia.

\section{Results}

A total of 100 participants were studied, 50 in the control group and 50 in the experimental group. The majority of the participants in the control group were 28-37-years-old and werefemales (73.6\%). The majority of the participants in the experimental group were in the age group of $18-27$ years, of which $73.7 \%$ were males (Table 1 ).

In this study, the overall incidence of awareness was $16 \%$. The incidence was higher in the control group (24\%) compared to that in the experimental group (8\%). In the control group, in those participants who had awareness, awareness was characterized by hearing conversation/music in $58.3 \%$, remembrance of intraoperative events in $41.6 \%$ and recall of dreams in $41.6 \%$. In the experimental group, awareness was pertained to dreaming in all the four participants (100\%) (Table 2).

The majority of the participants in the both the groups underwent cholecystectomy/hysterectomy (32\% in the control group and $16 \%$ in the experimental group). Some of the surgical procedures, like pyelolithotomy, lymphatic cyst excision, etc., were specific to the experimental group (Fig. 1).

The mean TCR time was higher in the experimental group (72.6 \pm 31.9 ) compared to that in the control group (42.5 \pm 21.1$)$. Among the participants in whom awareness was present, the experimental group had higher TCR time (67.8 \pm 7.6$)$ compared to the participants in the control group (35.8 \pm 20.0$)$. The association was statistically significant $(p<0.05)$ (Table 3$)$.

Table 1: Background characteristics of the study participants

\begin{tabular}{|c|c|c|c|c|c|c|c|}
\hline \multirow[b]{3}{*}{ S. no. } & \multirow[b]{3}{*}{ Age (in years) } & \multicolumn{6}{|l|}{ Group } \\
\hline & & \multicolumn{3}{|c|}{ Control $(N=50)$} & \multicolumn{3}{|c|}{ Experimental $(N=50)$} \\
\hline & & Male (\%) & Female (\%) & Total & Male (\%) & Female (\%) & Total \\
\hline 1 & $18-27$ & $5(38.5)$ & $8(61.5)$ & 13 & $14(73.7)$ & $5(26.3)$ & 19 \\
\hline 2 & $28-37$ & $5(26.3)$ & $14(73.6)$ & 19 & $8(50.0)$ & $8(50.0)$ & 16 \\
\hline 3 & $>37$ & $4(22.2)$ & $14(77.8)$ & 18 & $4(26.7)$ & $11(73.3)$ & 15 \\
\hline
\end{tabular}


Table 2: Awareness particulars between the two groups

\begin{tabular}{|c|c|c|c|c|c|}
\hline S. no. & Characteristic & Control $(N=50)$ & Experimental $(N=50)$ & Frequency $(N=100)$ & Percentage (\%) \\
\hline \multirow[t]{3}{*}{1} & Awareness & & & & \\
\hline & Aware & 12 & 4 & 16 & 16.0 \\
\hline & Not aware & 38 & 46 & 84 & 84.0 \\
\hline \multirow[t]{6}{*}{2} & Characteristics of awareness* & & & & \\
\hline & Remembrance of act of intubation & 0 & 0 & 0 & 0.0 \\
\hline & Dreaming & 5 & 4 & 9 & 39.1 \\
\hline & Hears conversation/music & 7 & 0 & 7 & 30.4 \\
\hline & Intraoperative events remembered & 5 & 0 & 5 & 21.7 \\
\hline & Unpleasant experience & 2 & 0 & 2 & 8.8 \\
\hline \multirow[t]{4}{*}{3} & Average anesthesia time & & & & \\
\hline & $0-60 \mathrm{~min}$ & 14 & 16 & 30 & 30.0 \\
\hline & $61-120 \mathrm{~min}$ & 31 & 24 & 55 & 55.0 \\
\hline & $>120 \mathrm{~min}$ & 5 & 10 & 15 & 15.0 \\
\hline
\end{tabular}

*Some participants had more than one response

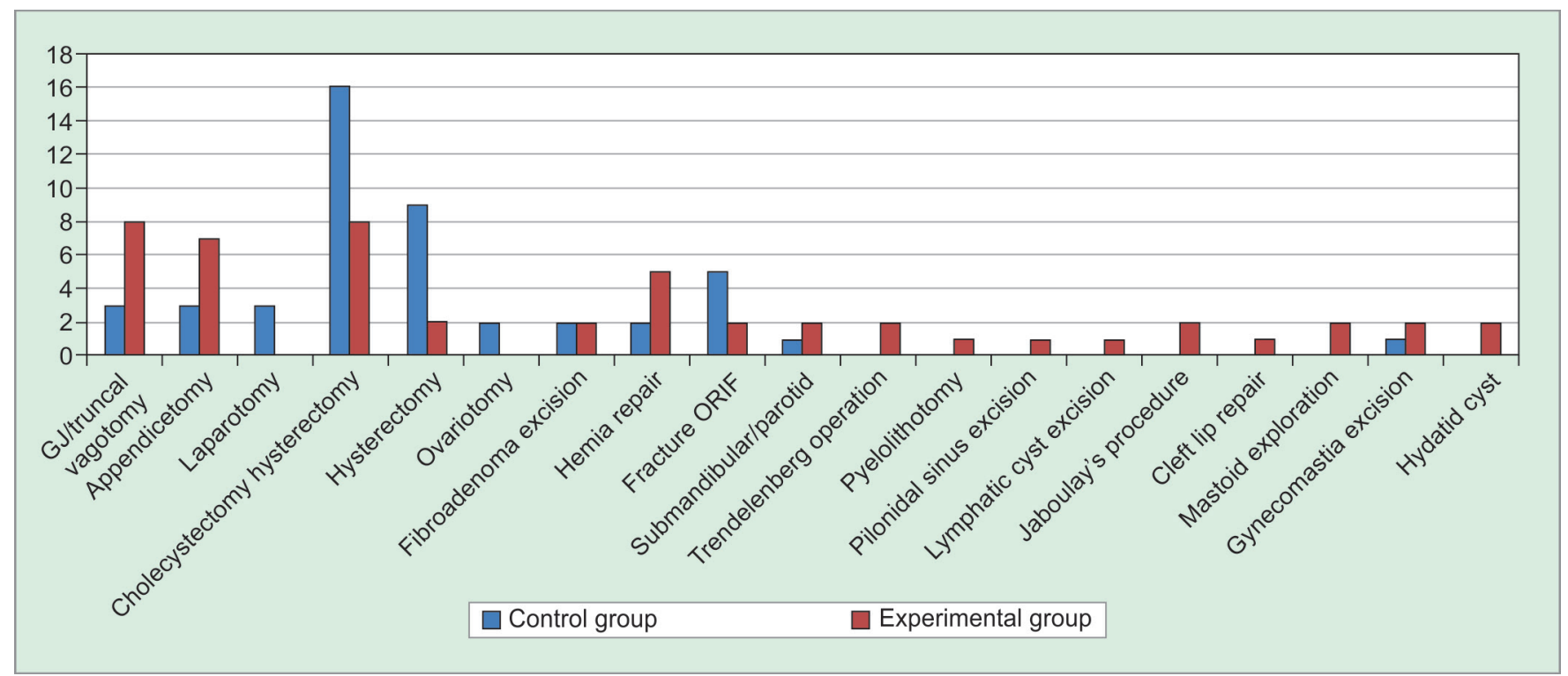

Fig. 1: Types of surgery

Table 3: Comparison of mean TCR time between two groups

\begin{tabular}{llllll}
\hline S.no. & Parameters & No. of cases & Mean (in sec) & Total mean time & p value \\
\hline 1 & Control group & & & & \\
& Awareness present & 12 & $35.8 \pm 20.0$ & $42.5 \pm 21.1$ & 0.05 \\
& Awareness absent & 38 & $44.4 \pm 22.5$ & & \\
2 & Experimental group & & & & 0.05 \\
& Awareness present & 4 & $67.8 \pm 7.6$ & $72.6 \pm 31.9$ & \\
& Awareness absent & 46 & $72.9 \pm 33.13$ & & \\
\hline
\end{tabular}

\section{Discussion}

The problem of awareness was first encountered with the introduction of muscle relaxant and pulmonary ventilation (Winter Bottom 1950). The implications of awareness under general anesthesia are many. The patient has an unpleasant experience which may result in posttraumatic stress disorder like sleep disturbances, nightmares, and daytime anxiety. There are several medicolegal implications associated with awareness warranting the anesthetists to exercise this facility with caution.
Benzodiazepines have been used for abolishing awareness under general anesthesia. In a study of Agarwal and Sikh, there was no incidence of recall of intraoperative events with diazepam 0.15 $\mathrm{mg} \mathrm{kg}^{-1}$ and atropine $0.6 \mathrm{mg} \mathrm{IM}$ premedication. ${ }^{1}$ Marshall Barr et al. in their study of obstetric patients reported an incidence of recall of intraoperative events of $2.1 \%$ and $1.1 \%$ when lorazepam $2 \mathrm{mg}$ and diazepam $10 \mathrm{mg}$, respectively, were administered following the extraction of the baby. ${ }^{2}$ In the studies of Parker et al. and De Roode et al., ${ }^{3,4}$ there was no incidence of recall of intraoperative events 
where midazolam was used as a premedicant. In our study, the incidence of recall of intraoperative events was nil and the incidence of intraoperative dreaming was $8 \%$ in the experimental group.

Dunnett et al. noted in their study that the recall of intubation was $1 \%$ under general anesthesia in patients who received no premedication. ${ }^{5}$ McKenna et al. reported an incidence of $2 \%$ with a similar technique. ${ }^{6}$ In another study by Marshall Barr et al., it was noted that there was no incidence or recall of intubation in patients undergoing cesarean section under general anesthesia without premedication. ${ }^{2}$ Westmoreland et al., Parker et al., and De Roode et al. reported no incidence of recall of intubation in patients who had received midazolam as premedication. In our study also, there was no incidence of recall of intubation. . $^{3,4,7}$

Agarwal and Sikh had an incidence of $0 \%$ for recall of intraoperative events in unpremedicated patients. ${ }^{1}$ Marshall Barr et al. had an incidence of $2.2 \%$ for the same. ${ }^{2}$ Our study showed a higher incidence of $18 \%$ in the control group for the recall of intraoperative events like remembrance of music and conversation heard during the intraoperative period. However, Marshall Barr et al. had used lorazepam, a benzodiazepine, which is known to have retrograde amnestic property, intraoperatively. ${ }^{2}$

In the experimental group, there was no recall of any intraoperative events, which concurs with the study of the other investigators. ${ }^{3,4,7}$ The incidence of intraoperative dreaming reported was $4.4 \%$ to $10.7 \%$ by Marshall Barr et al. ${ }^{2}$ This concurs with our study. Myles et al. reported an incidence or unpleasant experience of $3.2 \%$ in their study of patients undergoing surgery under general anesthesia with or without muscle relaxant and narcotic premedication and this was due to the awareness during anesthesia. ${ }^{8}$ In our study, in the control group, the incidence of unpleasant experience was slightly higher, i.e., $4 \%$ when compared to that of the above study, whereas in the experimental group, there was no incidence of unpleasant experience.

In our patients who showed awareness in the two groups, there were no signs suggestive of lighter planes of anesthesia like tachycardia, hypertension, lacrimation, or sweating. According to Russell et al., individually or in aggregate, physiological variables seemed to be of little value in predicting the consistency of patient's awareness under general anesthesia. ${ }^{9}$

In the study of awareness using the "TCR" test, Cormack reported a mean TCR time of 48 and 114 seconds after morphine and lorazepam premedication, respectively. ${ }^{10}$ In our study, the mean TCR time was significantly lesser than that in the control group. Even within the groups, the TCR time was significantly lesser in patients who had awareness than those who did not have awareness under general anesthesia $(p<0.05)$.

\section{Conclusion}

This study revealed that awareness under anesthesia is an ever present problem of the nitrous oxide, oxygen, and muscle relaxant technique of anesthesia. Awareness under anesthesia occurred in both the groups. Based on the results, we conclude the following:

- The incidence of awareness under general anesthesia was less in the experimental group who received midazolam as premedication.

- There was a significantly higher incidence of awareness under anesthesia in the patients who had received only atropine as premedication.

- In patients who had awareness under general anesthesia, the TCR was significantly lesser than those who did not have awareness. Thus, the TCR test is a simple, valuable, and reliable test in assessing awareness under general anesthesia.

Hence, it is recommended to include benzodiazepine like midazolam, a water-soluble agent, routinely as a premedicant to decrease the incidence of awareness.

\section{References}

1. Agarwal G, Sikh SS. Awareness during anaesthesia. Br J Anaesth 1977;49:835-883

2. Marshall Barr A, Moxon ANN, et al. The effect of diazepam and lorazepam on awareness during anaesthesia for caesarean section. Anaesthesia 1977;32:873-878.

3. Parker CJR, Oates JDL, et al. Memory for auditory material presented during anaesthesia. Br J Anaesth 1994;72:181-184.

4. De Roode A, Jelicic M, et al. The effect of midazolam premedication onimplicit memory activation during alfentanil-nitrous oxide anaesthesia. Anaesthesia 1995;50:191-194.

5. Dunnett IA. Awareness during endotracheal intubation, a comparison of ketamine and thiopentone. Br J Anaesth 1977;49:491-493.

6. McKenna T, Wilton TNP. Awareness during endotracheal intubation. Anaesthesia 1973;28:599-602.

7. Westmoreland CL, Sebel PS, et al. Indirect memory during anaesthesia. The effect of midazolam. Anaesthesiology 1993;78:237-241.

8. Myles PS, Williams DL, et al. Patient satisfaction after anaesthesia and surgery: results of a prospective surgery of 10811 patients. $\mathrm{Br} J$ Anaesthe 2001;84:6-10.

9. Russell IF. Midazolam-Alfentanil: An anaesthetic? An investigation using the isolated forearm technique. Br J Anaesth 1993;70:42-46.

10. Cormack RS. Awareness during surgery-a new approach. $\mathrm{Br} J$ Anaesth 1979;51:1051-1053. 